\title{
Effect of Terminal High Temperature on Chlorophyll Content and Normalized Difference Vegetation Index in Recombinant Inbred Lines of Bread Wheat
}

\author{
Sunita Sangwan*, Kirpa Ram, Pooja Rani and Renu Munjal \\ Department of Botany \& Plant Physiology, CCS Haryana Agricultural University, \\ Hisar, Haryana, India \\ *Corresponding author
}

\begin{abstract}
A B S T R A C T
Among the crops that feed human beings, Wheat (Triticum aestivum L.) is the second most important cool season crop in India. A drastic reduction in wheat production was observed due to increasing temperature. It has been estimated that global mean temperature is rising

Keywords

Chlorophyll content, Heat stress, Normalized difference vegetative index and recombinant inbred lines

Article Info

Accepted: 06 May 2018 Available Online: 10 June 2018 at $0.3 \%$ per decade which may cause 50\% decline in wheat yields in South Asia by 2050 . High temperature above than optimum has drastic effect on chlorophyll content which is also reflected by normalized difference vegetative index (NDVI). This experiment was conducted in an experimental field of the Wheat and Barley section, department of Genetics and Plant Breeding, CCSHAU, Hisar, during November to April 2015-16 and 2016-17 In this study, we evaluated chlorophyll content using SPAD and NDVI with the Green Seeker ${ }^{\mathrm{TM}}$ Handheld Optical Sensor Unit on recombinant inbred lines (RILs) of bread wheat derived from WH1021 (heat tolerant) and WH711 (heat sensitive) wheat genotypes. RILs were assessed for these spectral indices under two sowing dates i.e. normal and late sown during 2015-16 and 2016-17. Measurements were made at anthesis and 10 days after anthesis. Heat stress has significant negative effect on the leaf chlorophyll content. Average chlorophyll content and NDVI decreases as the temperature increase. A contrasting difference was observed in timely sown and late sown at 10 days after anthesis for both spectral indices. The result of this study may prove useful in the selection of physiologically efficient heat tolerant genotypes.
\end{abstract}

\section{Introduction}

Among the crops that feed human beings, Wheat (Triticum aestivum L.) is the second most important cool season crop in India after rice contributing significantly to the national food security. India has also second largest area (26.3 mha) under wheat cultivation in the world followed by China (22.5 mha) (FAOSTAT, 2017). Wheat yields are challenged by both biotic and abiotic stress. Global warming is predicted to increase the frequency and severity of heat stress leading to drastic reduction in the food production (Talukder et al., 2014). It has been estimated that global mean temperature is rising at $0.3 \%$ per decade which may cause $50 \%$ decline in wheat yields in South Asia by 2050. This is due to the heat stress that causes an array of physiological, biochemical and morphological 
changes in wheat (Wahid et al., 2007). Under heat stress conditions, significant correlation was observed between loss of chlorophyll and reduction in NDVI Since chlorophyll content and NDVI are associated with heat stress, measurements of chlorophyll content using a chlorophyll meter and NDVI using a Green Seeker will be useful as a method for high throughput screening for heat tolerance in wheat (Sharma et al., 2015). Heat stress has significant negative effect on the leaf chlorophyll content however, the reduction is time dependent. Reduction in total chlorophyll content is related with photosynthesis reduction as a result of reduced antenna size and thus less light harvesting during heat stress (Al-Khatib and Paulsen, 1984; Blum, 1986; Harding et al., 1990; Shanmugam et al., 2013). High temperature damage photosynthetic membrane and resulted in chlorophyll loss (Al-Khatib and Paulsen, 1984) and ultimately resulted in lower grain yield (Wheelar et al., 1996; Ferris et al., 1998; Gibson and Paulsen, 1999).

Heat stress exposures reduce the chlorophyll synthesis and enhance its loss (Tewari and Tripathy, 2012). Loss of chlorophyll is associated with membrane damage (Ristic et al., 2007) and leaf senescence (Al-Khatib and Paulsen, 1984). In wheat delayed senescence or stay green trait showed association with heat tolerance because of their contribution to a longer grain filling period ultimately resulted in yield gain under heat stress (Reynolds et al., 1997; Vijayalakshmi et al., 2010). Wheat line affected by high temperature at anthesis and later stages showed reduction in biomass, grain filling duration and thousand grain weight but this reduction is dependent on stay green ability of wheat plant (Kumari et al., 2013). Plants with stay green traits showed stable chlorophyll content and high Fv/Fm ratio (Al-Khatib and Paulsen, 1990; Vijayalakshmi et al., 2010). Maintenance of high chlorophyll content in wheat is a desirable trait in breeding for heat tolerance which leads to low degree of photoinhibition at high temperature (Ristic et al., 2007; Talebi, 2011). Normalized difference vegetation index (NDVI) is a unified estimate of both ground cover (leaf area) and nitrogen content of canopy (Pinto et al., 2010). NDVI showed association with chlorophyll content, leaf nitrogen content and ultimately with photosynthetic efficiency of plant (Tattaris et al., 2016). NDVI is also a measure of crop biomass and crop senescence rate (Olivaresvillegas et al., 2007). High valve of NDVI along with high chlorophyll content and longer stay green traits during high temperature conditions showed association with heat tolerance in wheat (Feng et al., 2014; Cao et al., 2015). High chlorophyll content cooler canopies and maximum NDVI showed association with each other and induced heat tolerance (Ramya et al., 2015; Munjal and Dhanda, 2016; Ram et al., 2017). Lopes and Reynolds (2012) reported positive correlation of NDVI at physiological maturity with grain yield under heat stress and heat stress combined with drought environments.

\section{Materials and Methods}

\section{Plant material}

The plant material consisted of a mapping population of RILs developed from a cross between a comparatively late sown heat tolerant genotype WH1021 and a heat susceptible agronomical beneficial genotype WH711. RILs were obtained from Wheat and Barley section, Department of Genetics and Plant Breeding, CCS HAU, Hisar, Haryana, India.

\section{Experiment layout}

The RILs along with parents were sown at field of Wheat and Barley Section, Department of Genetics and Plant Breeding, 
CCSHAU, Hisar, during two crop seasons 2015-16 and 2016-17 under two planting conditions, timely sown (November 20, 2015 \&November 14, 2016) and late sown (December 22, 2015 and December 16, 2016).

All experiments were conducted under irrigated conditions with augmented design in 2015-16 and randomized complete block design (RBD) in 2016-17.

\section{Package practices}

Recommended package of practices for the agro-climatic zone were followed during the experiment.

The practices included were land preparation, fertilizer application, sowing, irrigation, weeding and harvesting.

Thus, the seed rate used was $1.5 \mathrm{~g} / \mathrm{m} .50$ $\mathrm{Kg} / \mathrm{ha}$ of compound DAP (60N:24P:12K) was used as basal dressing and $110 \mathrm{~kg} / \mathrm{ha}$ of urea was applied as top dressing. Planting, weeding and harvesting operations were done manually. $1 \%$ solution of 25 EC tilt was sprayed to protect the crop from disease.

\section{Measurement of chlorophyll content and normalized difference vegetation index}

Chlorophyll content and NDVI were measured at two stages, stage1 (at anthesis) and stage2 (at 10 days after anthesis) by selecting five plants from each row. In this study a handheld battery portable optical meter (e.g., Minolta SPAD-502 chlorophyll meter) which measures the chlorophyll content via light transmittance (absorbance of red light at 650 $\mathrm{nm}$ and infrared light at $940 \mathrm{~nm}$ ), was used to quickly and nondestructively measure flag leaf chlorophyll. NDVI measurements were taken with the Green Seeker ${ }^{\mathrm{TM}}$ Handheld Optical Sensor Unit (Trimble Navigation Limited, US).

\section{Grain yield per plant (g)}

Five plants were selected from each row, harvesting and threshed separately. The threshed grains were cleaned and yield was recorded in $\mathrm{g}_{\text {plant }}{ }^{-1}$.

\section{Statistical analysis}

Pearson's correlation between various yield components was performed by using OPSTAT software available at CCSHAU website hau.ernet.in. The mean comparison was calculated by percent variation of yield and yield components between timely sown and late sown conditions during both years.

\section{Results and Discussion}

\section{Analysis of variance}

Result of analysis of variance indicated significant variation for chlorophyll content at $1 \%$ probability level among genotypes, over the years i.e. 2015-16 and 2016-17, environments i.e. timely sown and late sown, interactions $\mathrm{G} \times \mathrm{Y}, \mathrm{G} \times \mathrm{E}, \mathrm{E} \times \mathrm{Y}$ and $\mathrm{G} \times \mathrm{Y} \times \mathrm{E}$. this revealed the variability among the genotypes and environment.

Results of analysis of variance for normalized difference vegetative index (NDVI) at stage1 and stage 2 indicated significant variation at $1 \%$ significance level among genotypes, over the environments and years. Interaction between genotypes, environment and year also showed significant variation at $1 \%$ probability level (Table 1) but interaction of year with environment was non-significant.

Grain yield per plant has significant variation at $1 \%$ probability level among the genotypes, environments, years and their interaction (Table 1) except interaction of genotypes with environment which was non-significant, as determined by analysis of variance. 


\section{Mean performance}

\section{Chlorophyll content}

\section{At stage1}

In heat tolerant parent WH1021chlorophyll content of flag leaves at stage1 was 32.7 and 31.5under timely sown during 2015-16 and 2016-17 crop season while, under late sown it was 30.7 and 29.7 respectively. Chlorophyll content in heat susceptible parent WH711 was 28.6 and 24.6 under late sown condition; less by 16.86 and $23.84 \%$ than timely sown during crop season 2015-16 and 2016-17, respectively.

Among RILs chlorophyll content at stage1 ranged from 22.8 to 34.7 in $2015-16$ and 23.8 to 35.4 in $2016-17$ crop seasons under timely and 20.2 to 31.1 and 21.3 to 30.3 under late sown for the same crop seasons. In late sown crop, chlorophyll content of flag leaves at stage 1 among RILs was reduced by 14.43 and $14.30 \%$ during crop season 2015-16 and 201617 , respectively (Table 3). Mean chlorophyll content at stage 1 is presented in Table 2 while, reduction over the years due to late sown is depicted in Figure 1(A).

\section{At stage2}

Chlorophyll content at stage2 in WH1021 was 30.3 and 29.3 under timely sown during 201516 and 2016-17 crop year, respectively and 26.1 and 23.2 under late sown for the corresponding crop years. In WH711 chlorophyll content 27.2 and 27.3 under timely sown, while in late sown chlorophyll content was reduced by 28.68 and $38.10 \%$ during 2015-16 and 2016-17, respectively. In RILs population chlorophyll content ranged from 20.5 to 30.4 during 2015-16 and 21.7 to 29.3 during 2016-17 under timely sown while it was 11.2 to 26.7 in 2015-16and 12.1 to 26.8 in 2016-17 under late sown conditions.
Chlorophyll content in RILs decreased under late sown condition by 22.99 and $22.61 \%$ over timely sown during the two corresponding years. Percent variation due to late sown over the years is presented in Table 3 and mean number of chlorophyll content of flag leaf at stage 2 is presented in Table 2.

\section{Normalized difference vegetative index}

\section{At stage1}

In heat tolerant parent WH1021normalized difference vegetative index (NDVI) at stage1 was 0.82 and 0.83 under timely sown during 2015-16 and 2016-17 crop season while, under late sown it was 0.74 and 0.75 . NDVI in heat susceptible parent WH711 was 0.63 and 0.61 under late sown condition; less by 20.25 and $23.75 \%$ than timely sown during crop season 2015-16 and 2016-17, respectively.

Among RILs normalized difference vegetative index at stage 1 ranged from 0.56 to 0.94 in 2015-16 and 0.71 to 0.87 in 2016-17 crop season under timely sown and 0.51 to 0.77 and 0.41 to 0.80 under late sown for the same crop seasons. In late sown crop, NDVI at stage1 among RILs was reduced by 17.72 and $19.75 \%$ during crop season 2015-16 and 201617, respectively (Table 3). Mean NDVI at stage 1 is presented in Table 2 while, reduction over the years due to late sown is depicted in Figure 1(B).

\section{At stage 2}

Normalized difference vegetative index at stage2in WH1021 was 0.71 and 0.70 under timely sown during 2015-16 and 2016-17 crop year, respectively and 0.65 and 0.68 under late sown for the corresponding crop years. In WH711 NDVI was 0.66 and 0.63 under timely sown, while in late sown NDVI was reduced by 10.61 and $12.70 \%$ during $2015-16$ and 2016-17, respectively. 
Fig.1 Percent variation in timely sown over late sown in physiological traits Grain yield observed in parents and RILs of WH1021/WH711 during 2015-16 and 2016-17. A: Chlorophyll content (CHC), B: Normalized difference vegetative index (NDVI) and C: Grain yield/Plant




Table.2 Mean and range of Chlorophyll content (SPAD unit), NDVI and Grain yield/plant under timely and late sown conditions during 2015-16 and 2016-17 for parents and recombinant inbred lines (RILs)

\begin{tabular}{|c|c|c|c|c|c|c|c|c|c|c|}
\hline \multirow[t]{3}{*}{ Year } & \multirow[t]{3}{*}{ Physiological traits } & \multirow[t]{3}{*}{ Stages } & \multicolumn{2}{|c|}{ WH1021 } & \multicolumn{2}{|c|}{ WH711 } & \multicolumn{4}{|c|}{ RILs } \\
\hline & & & \multirow[t]{2}{*}{ Timely } & \multirow[t]{2}{*}{ Late } & \multirow[t]{2}{*}{ Timely } & \multirow[t]{2}{*}{ Late } & \multicolumn{2}{|c|}{ Mean } & \multicolumn{2}{|c|}{ Range } \\
\hline & & & & & & & Timely & Late & Timely & Late \\
\hline \multirow{7}{*}{$\begin{array}{l}2015- \\
16\end{array}$} & \multirow[t]{3}{*}{ chlorophyll content } & $\mathbf{S}_{1}$ & $32.7 \pm 0.60$ & $30.7 \pm 0.39$ & $34.4 \pm 1.04$ & $28.6 \pm 0.37$ & $29.1 \pm 0.65$ & $24.9 \pm 1.00$ & $22.8-34.7$ & $20.2-31.1$ \\
\hline & & $\mathbf{S}_{2}$ & $30.3 \pm 0.38$ & $26.1 \pm 1.05$ & $27.2 \pm 1.05$ & $19.4 \pm 0.75$ & $26.1 \pm 1.14$ & $20.1 \pm 0.82$ & $20.5-30.4$ & $11.2-26.7$ \\
\hline & & Mean & 31.5 & 28.4 & 30.8 & 24.0 & 27.6 & 22.5 & $21.6-32.5$ & $15.7-28.9$ \\
\hline & \multirow{3}{*}{$\begin{array}{c}\text { Normalized difference } \\
\text { vegetation index (NDVI) }\end{array}$} & $\mathbf{S}_{1}$ & $0.82 \pm 0.01$ & $0.74 \pm 0.02$ & $0.79 \pm 0.1$ & $0.63 \pm 0.01$ & $0.79 \pm 0.02$ & $0.65 \pm 0.01$ & $0.56-0.94$ & $0.51-0.77$ \\
\hline & & $\mathbf{S}_{2}$ & $0.71 \pm 0.02$ & $0.65 \pm 0.01$ & $0.66 \pm 0.03$ & $0.59 \pm 0.01$ & $0.67 \pm 0.02$ & $0.59 \pm 0.01$ & $0.56-78$ & $0.43-69$ \\
\hline & & Mean & 0.77 & 0.70 & 0.73 & 0.61 & 0.73 & 0.62 & $0.56-0.86$ & $0.47-0.73$ \\
\hline & \multicolumn{2}{|l|}{ Grain yield(g)/plant } & $11.36 \pm 0.04$ & $8.91 \pm 0.02$ & $15.21 \pm 0.01$ & $7.34 \pm 0.01$ & $13.50 \pm 0.13$ & $7.82 \pm 0.10$ & $6.59-17.45$ & $3.78-11.25$ \\
\hline \multirow{7}{*}{$\begin{array}{c}2016- \\
17\end{array}$} & \multirow[t]{3}{*}{ chlorophyll content } & $S_{1}$ & $31.5 \pm 0.38$ & $29.7 \pm 0.55$ & $32.3 \pm 0.18$ & $24.6 \pm 0.53$ & $29.2 \pm 1.06$ & $25.1 \pm 1.07$ & $23.8-35.40$ & $21.3-30.3$ \\
\hline & & $\mathbf{S}_{2}$ & $29.3 \pm 0.49$ & $23.2 \pm 0.30$ & $27.3 \pm 1.35$ & $16.9 \pm 0.26$ & $26.18 \pm 1.15$ & $20.26 \pm 1.01$ & $21.7-29.3$ & $12.1-26.8$ \\
\hline & & Mean & 30.4 & 26.5 & 29.8 & 20.8 & 27.7 & 22.7 & $22.8-32.4$ & $16.7-28.55$ \\
\hline & \multirow{3}{*}{$\begin{array}{c}\text { Normalized difference } \\
\text { vegetation index (NDVI) }\end{array}$} & $\mathbf{S}_{1}$ & $0.83 \pm 0.02$ & $0.75 \pm 0.02$ & $0.80 \pm 0.02$ & $0.61 \pm 0.01$ & $0.81 \pm 0.01$ & $0.65 \pm 0.02$ & $0.71-0.87$ & $0.41-0.80$ \\
\hline & & $\mathbf{S}_{\mathbf{2}}$ & $0.70 \pm 0.02$ & $0.68 \pm 0.01$ & $0.63 \pm 0.02$ & $0.55 \pm 0.03$ & $0.66 \pm 0.02$ & $0.60 \pm 0.01$ & $0.53-0.79$ & $0.45-0.73$ \\
\hline & & Mean & 0.77 & 0.72 & 0.72 & 0.58 & 0.74 & 0.63 & $0.62-0.83$ & $0.43-0.77$ \\
\hline & \multicolumn{2}{|l|}{ Grain yield(g)/plant } & $11.81 \pm 0.33$ & $9.25 \pm 0.05$ & $13.66 \pm 0.73$ & $7.74 \pm 0.20$ & $14.25 \pm 0.23$ & $8.29 \pm 0.13$ & $5.60-21.00$ & $2.66-15.57$ \\
\hline
\end{tabular}

\pm standard error

RILs- recombinant inbred lines, $\mathrm{S}_{1}$ - at Stage1, $\mathrm{S}_{2}$ - at stage2

Table.3 Percent reduction in chlorophyll content (SPAD unit), NDVI and grain yield/plant in parents and recombinant inbred lines (RILs) during 2015-16 and 2016-17

\begin{tabular}{|c|c|c|c|c|c|c|c|}
\hline \multirow{2}{*}{ Traits } & \multirow[t]{2}{*}{ Stages } & \multicolumn{2}{|c|}{ WH1021 } & \multicolumn{2}{|c|}{ WH711 } & \multicolumn{2}{|c|}{ RILs } \\
\hline & & 2015-16 & 2016-17 & 2015-16 & 2016-17 & 2015-16 & 2016-17 \\
\hline \multirow[t]{2}{*}{ Chlorophyll content } & $\mathbf{S}_{1}$ & 6.12 & 5.71 & 16.86 & 23.84 & 14.43 & 14.30 \\
\hline & $\mathbf{S}_{\mathbf{2}}$ & 13.86 & 20.82 & 28.68 & 38.10 & 22.99 & 22.61 \\
\hline \multirow[t]{2}{*}{ NDVI } & $\mathbf{S}_{1}$ & 9.76 & 9.64 & 20.25 & 23.75 & 17.72 & 19.75 \\
\hline & $\mathbf{S}_{\mathbf{2}}$ & 8.45 & 2.86 & 10.61 & 12.70 & 11.94 & 9.09 \\
\hline \multicolumn{2}{|c|}{ Grain yield/plant } & 21.63 & 21.64 & 51.75 & 43.31 & 42.10 & 41.88 \\
\hline
\end{tabular}

RILs- recombinant inbred lines, $\mathrm{S}_{1}$ - at Stage $1, \mathrm{~S}_{2}$ - at stage2 
Table.1 Mean sum of squares for chlorophyll content, normalized difference vegetative index (at stage 1 and stage 2) and grain yield/plant in recombinant inbred lines of WH1021/WH711 over the years and environments

\begin{tabular}{|c|c|c|c|c|c|c|}
\hline \multirow{2}{*}{$\begin{array}{l}\text { Source of } \\
\text { Variation }\end{array}$} & \multirow[t]{2}{*}{ df } & \multicolumn{2}{|c|}{ Chlorophyll content } & \multicolumn{2}{|c|}{ NDVI } & \multirow{2}{*}{$\begin{array}{c}\text { Grain } \\
\text { yield/plant }\end{array}$} \\
\hline & & Stage1 & Stage2 & Stage1 & Stage2 & \\
\hline Replication & 2 & 4.615 & $16.131 * *$ & 0.007 & 0.001 & 0.105 \\
\hline Genotype (G) & 81 & $41.117 * *$ & $41.674 * *$ & $0.03 * *$ & $0.013 * *$ & $19.064 * *$ \\
\hline $\operatorname{Year}(Y)$ & 1 & $3426.725 * *$ & $7280.221 * *$ & $3.707 * *$ & $0.315^{* *}$ & $8260.584 * *$ \\
\hline $\begin{array}{c}\text { Environment } \\
\text { (E) }\end{array}$ & 1 & $24.658 * *$ & $77.038 * *$ & $0.466 * *$ & $0.211^{* *}$ & $87.515^{* *}$ \\
\hline Gx Y & 81 & $13.330 * *$ & $20.141 * *$ & $0.046 * *$ & $0.007 * *$ & $11.966 * *$ \\
\hline $\mathbf{G} \times \mathbf{E}$ & 81 & $12.385^{* *}$ & $21.14 * *$ & $0.021 * *$ & $0.01 * *$ & $18.176 * *$ \\
\hline $\mathbf{Y} \times \mathbf{E}$ & 1 & $43.398 * *$ & $65.240 * *$ & $1.978 * *$ & $0.151 * *$ & $4.123 * *$ \\
\hline Gx Y $\times \mathbf{E}$ & 81 & $8.296 * *$ & $9.383 * *$ & $0.031 * *$ & $0.008 * *$ & $11.927 * *$ \\
\hline Error & 654 & & & & & \\
\hline
\end{tabular}

Among RILs populations NDVI ranged from 0.56 to 0.78 during $2015-16$ and 0.53 to 0.79 during 2016-17 under timely sown while it was 0.43 to 0.69 in $2015-16$ and 0.45 to 0.73 in 2016-17 under late sown conditions. NDVI in RILs decreased under late sown condition by 11.94 and $9.09 \%$ over timely sown during the two corresponding years. Percent variation in NDVI due to late sown over the years is presented in Table 3 and mean performance of NDVI at stage 2 is presented in Table 2.

\section{Grain yield/plant}

Average grain yield in heat tolerant parent WH1021 was recorded as 11.363 and 11.810 $\mathrm{g}$ under timely sown and 8.905 and $9.254 \mathrm{~g}$ under late sown during 2015-16 and 2016-17 crop seasons, respectively. Grain yield in heat susceptible parent WH711 was 7.340 and $7.734 \mathrm{~g}$ under late sown which was 51.7 and $43.3 \%$ lesser than timely sown during 201516 and 2016-17, respectively. In case of RILs grain yield ranged from 6.587 to $17.449 \mathrm{~g}$ with an average of $13.503 \mathrm{~g}$ during 2015-16 and 5.600 to $21.000 \mathrm{~g}$ and average $14.254 \mathrm{~g}$ during 2015-16 under timely sown while, from 3.775 to $11.252 \mathrm{~g}$ and having average $7.818 \mathrm{~g}$ during $2015-16$ and 2.658 to $15.567 \mathrm{~g}$ with an average of $8.285 \mathrm{~g}$ during 2016-17 under late sown condition. A reduction of 42.1 and $41.8 \%$ was recorded due to late sowing during 2015-16 and 2016-17, respectively. Mean grains yield/plant is presented in Table 2 and percent reduction is depicted in Figure 1(C).

NDVI has been proposed as a means of estimating chlorophyll (Munden et al., 1994), biomass (Babar et al., 2006), ground-cover (Mullan and Reynolds, 2010), and yield in wheat and other cereals (Royo et al., 2003). Many other studies have shown that the Green Seeker sensor can be useful to determine and integrate remotely the total greenness of wheat plots (Hansen and Schjoerring, 2003; Babar et al., 2006; Marti et al., 2007). The NDVI also gives a continuous measurement of stay-green and can substitute discrete scores obtained by subjective visual observations

The response of parents and RILs population to heat stress differentiate with the trait in terms of reduction. In present study heat 
susceptible parent WH711 suffered higher reduction in chlorophyll content (CHC), normalized difference vegetation index (NDVI) at anthesis and 10 days after anthesis than heat tolerant WH1021 under late sown conditions over both the crop seasons (Figure 1). WH1021 maintained its performance under stress conditions due to tolerance yet, the extent of reduction was higher during 2015-16 as compared to 2016-17 crop seasons. This was due to the difference in minimum and maximum temperature under late sown conditions which was higher in 2015-16 than 2016-17 and high temperature from 1st to 3rd week of March in 2015-16 than in 2016-17 crop seasons. RILs also followed the same trends like parents to high temperature with variations in Chlorophyll content and NDVI. Maximum reduction recorded in chlorophyll content $(22.99 \%$, $22.61 \%)$ and NDVI $(17.72 \%, 19.75 \%)$ at 10 days after anthesis during both years.

\section{High-temperature stress causes} photosynthesis reduction through disruptions in the structure and function of chloroplasts and reductions in chlorophyll content in wheat leaves [Brestic et al., 2016; Sunita et al., 2017 (a)]. Reduction in chlorophyll content during grain filling under heat stress in field condition was reported to be associated with reduced yield [Reynolds et al., 1994, Ram et al., 2017 and Sunita et al., 2017 (b)] which is also reported during this study. NDVI is usually associated with the plant biomass production and yield performance (Ram et al., 2017).

Due to the positive correlation of NDVI with chlorophyll content and photosynthetic rate it might be a useful trait for developing heat tolerant wheat genotypes. Photosynthesis is dependent upon chlorophyll for the absorption of sunlight. Thus, a reduction in leaf chlorophyll content during reproductive stage has been shown to negatively influence yields. To combat premature senescence due to heat stress, the "stay green trait" is generally recognized as the plant's ability to retain chlorophyll under stressful conditions. So NDVI and Chlorophyll content can be useful parameters for evaluating the heat stress and by maintain less variation in these two at high temperature the yield of wheat can be improved.

\section{Acknowledgement}

The authors wish to express special thanks to Council of Scientific and Industrial Research (CSIR), India, for the financial support to complete this research work.

\section{References}

Al-Khatib, K. and Paulsen, G.M. 1984. Mode of high-temperature injury to wheat during grain development. Plant Phy., 61: 363-368.

Al-Khatib, K. and Paulsen, G.M. 1990. Photosynthesis and productivity during high temperature stress of wheat genotypes from major world regions. Crop Sci., 30: 1127-1132.

Babar, M.A., Reynolds, M.P., van Ginkel, M., Klatt, A.R., Raun, W.R. and Stone, M.L. 2006. Spectral reflectance indices as potential indirect selection criteria for wheat yield under irrigation. Crop Sci., 46: 578-588.

Blum, A. 1986. The effect of heat stresses on wheat leaf and ear photosynthesis. J. Exp. Bot., 37: 111-118.

Brestic, M., Ziveak, M., Kunderlikova, K. and Allakhverdieve, S.I. 2016. High temperature specially affects the photoprotective responses of chlorophyll-b-deficient wheat mutant lines. Photosynthesis research.

Cao, X., Mondal, S., Cheng, D., Wang, C., Liu, A., Song, J. and Liu, J. 2015. Evaluation of agronomic and 
physiological traits associated with high temperature stress tolerance in the winter wheat cultivars. Acta Physiol Plant, 37: 90-92.

FAO. 2017. FAO Statistical Databases. Food and Agriculture Organization of the United Nations. http://faostat.fao.org

Feng, B., Liu, P., Li, G., Dong, S.T., Wang, F.H., Kong, L.A. and Zhang, J.W. 2014. Effect of Heat Stress on the Photosynthetic Characteristics in Flag Leaves at the Grain-Filling Stage of Different Heat-Resistant Winter Wheat Varieties. J Agron Crop Sci, 200:143155.

Ferris, R., Ellis, R.H. and Hadley, W. 1998. Effect of high temperature stress at anthesis on grain yield and biomass of field-grown crops of wheat. Ann Botany, 82: 631-639.

Gibson, L.R. and Paulsen, G.M. 1999. Yield components of wheat grown under high temperature stress during reproductive growth. Crop Sci., 39: 1841-1846.

Harding, S. A., Guikema, G. A. and Paulsen, G. M. 1990. Photosynthetic decline from high temperature stress during maturation of wheat. II Interaction with source and sink processes. Plant Physiol, 92: 654-658.

Kumari, M., Pudake, R.N., Singh, V.P. and Joshi, A.K. 2013. Association of staygreen trait with canopy temperature depression and yield traits under terminal heat stress in wheat (Triticum aestivum L.). Euphytica, 190: 87-97.

Lopes, M.S., Reynolds, M.P., Jalal-Kamali, M.R., Moussa, M., Feltaous, Y., Tahir, Baum, M. 2012. The yield correlations of selectable physiological traits in a population of advanced spring wheat lines grown in warm and drought environments. Field Crop Res., 128: 129-136.

Mullan D.J. and Reynolds M.P. 2010. Quantifying genetic effects of ground cover on soil water evaporation using digital imaging. Funct. Plant Biol., 37: 703-712.

Munden, R., Curran, P. J. and Catt, J. A. 1994. The relationship between red edge and chlorophyll concentration in the Broad-balk winter wheat experiment at Rothamsted. Int. J. Remote Sens. 15: 705-709.

Munjal, R. and Dhanda, S. S. 2016. Assessment of drought resistance in Indian wheat cultivars for morphophysiological traits. Ekin J. Crop Breed. Genet. 2(1): 74-81

Olivares-villegas, J. J., Reynolds, M. P. and McDonald, G.K. 2007. Droughtadaptive attributes in the Seri/Babax hexaploid wheat population. Funct. Plant Biol. 34: 189-203.

Pinto, R.S., Reynolds, M.P., Mathews, K.L., McIntyre, C.L., Olivares-Villegas, J.J. and Chapman, S.C. 2010. Heat and drought adaptive QTL in a wheat population designed to minimize confounding agronomic effects. Theor. Appl. Genet. 121: 1001-1021.

Ram, K., Munjal, R., Sunita and Kumar, N. 2017. Evaluation of chlorophyll content index and normalized difference vegetation index as indicators for combine effects of drought and high temperature in bread. Int. J. Curr. Microbiol. Appl. Sci. 6(3): 528-534.

Ramya, P., Jain, N., Singh, G. P., Singh, P. K. and Prabhu, K. V. 2015. Population structure, molecular and physiological characterisation of elite wheat varieties used as parents in drought and heat stress breeding in India. Indian J. Genet. Pl. Breed. 75: 250-252.

Reynolds, M. P., Balota, M., Delgado, M.I.B., Amani, J. and Fischer, R.A. 1994. Physiological and morphological traits associated with spring wheat yield under hot, irrigated conditions. Aust. J. Plant Physiol. 21: 717-730. 
Reynolds, M.P., Nagarajan, S., Razzaque, M.A. and Ageeb, O.O.A. (eds.). 1997. Using canopy temperature depression to select for yield potential of wheat in heat stressed environments. Wheat special report No. 42. CIMMYT Mexico.

Ristic, Z., Bukovnik, U. and Prasad, P.V.V. 2007. Correlation between heat stability of thylakoid membranes and loss of chlorophyll in winter wheat under heat stress. Crop Sci. 47: 2067-2073.

Royo, C., Villegas, D., García del Moral, L. F., El Hani, S., Aparicio, N., ... Rharrabti Y. 2002. Comparative performance of carbon isotope discrimination and canopy temperature depression as predictors of genotype differences in durum wheat yield in Spain. Aust. J. Agric. Res. 53: 561-569.

Shanmugam, S., Kjaer, K. H., Ottosen, C.O., Rosenqvist, E., Kumari, S. and Wollenweber B. 2013. The alleviating effect of elevated $\mathrm{CO} 2$ on heat stress susceptibility of two wheat (Triticum aestivum L.) cultivars. J. Agron Crop Sci. 199: 340-50.

Sharma, D., Mamrutha, H. M., Gupta, V.K., Tiwari, R. and Singh, R. 2015. Association of SSCP variants of HSP genes with physiological and yield traits under heat stress in wheat, Res. Crops. 16(1): 139-146.

Talebi, R. 2011. Evaluation of chlorophyll content and canopy temperature as indicators for drought tolerance in durum wheat (Triticum durum Desf.). Aust. J. Basic Appl. Sci., 5: 1457-1462. Talukder, S., Babar, M., Vijayalakshmi, K., Poland, J., Prasad, P., Bowden, R. and Fritz, A. 2014. Mapping QTL for the traits associated with heat tolerance in wheat (Triticum aestivum L.). BMC Genet. 15: 97.

Tattaris, M., Reynolds, M. P. and Chapman S. C. 2016. A direct comparison of remote sensing approaches for high-throughput phenotyping in plant breeding. Front. Plant Sci. 7: 1131

Tiwari, A.K. and Tripathy, B.C. 2012. Temperature Stress Induced Impairment of Chlorophyll Biosynthetic Reactions in Cucumber and Wheat. Plant Physiol. 117: 3851-58.

Vijayalakshmi, K., Fritz, A., Paulsen, G., Bai, G., Pandravada, S. and Gill, B. 2010. Modeling and mapping QTL for senescence-related traits in winter wheat under high temperature. Mol. Breed. 26: 163-175.

Wahid, A., Gelani, S., Ashraf, M. and Foolad, M.R. 2007. Heat tolerance in plants: an overview. Environ. Exp. Bot. 61: 199223.

Wheeler, T. R., Hong, T. D., Ellis, R. H., Batts, G. R., Morison, J. I. L., and Hadley, P. (1996). The duration and rate of grain growth, and harvest index, of wheat (Triticum aestivum $\mathrm{L}$ ) in response to temperature and CO2. J. Exp. Bot. 47(298): 623-630.

\section{How to cite this article:}

Sunita Sangwan, Kirpa Ram, Pooja Rani and Renu Munjal. 2018. Effect of Terminal High Temperature on Chlorophyll Content and Normalized Difference Vegetation Index in Recombinant Inbred Lines of Bread Wheat. Int.J.Curr.Microbiol.App.Sci. 7(06): 1174-1183. doi: https://doi.org/10.20546/ijcmas.2018.706.139 